\title{
对制訂化学工業方面研究工作 計划的意見
}

\author{
侯 德 榜 \\ （重工業部技術顧問，中國科学院技形科学部委員）
}

我們一定要根据國家淮会主义經济經設的需要，來制訂科学㸴究工作計划。存现在 社会主义建設的高潮中，我們正在新建或演建砤多工梁。全國的資本主义工商業的社会 主义改造已取得很大的成就。農業合作化运动高潮正在繼䍃澎湃發展。这些都要求技術 科学研究工作与其配合。这就问我們提出了許多研究問題。因此就必須充分㖟揮全國科 学工作者的力量, 來做好这些研究工作。

我現在就我們关于1956年和1957年的方針任务，及今后的長远棓划，提出一些甞是。 这些意見是有关化工方面的研究工作的，大部分屬于無机工業化学的范㨐。掺言之，即

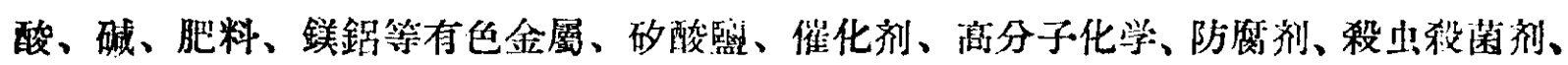
同位素及原子能的和本应用等呼究间題。

在酸的方面，应考虑四酸，卯硫酸、确酸、監酸、磷酸。硫酸工業在我國已有一些

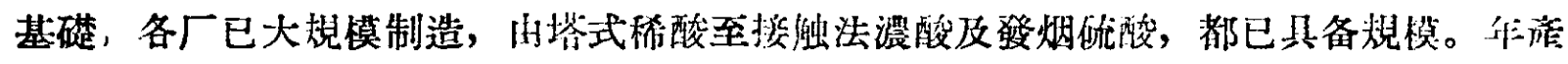

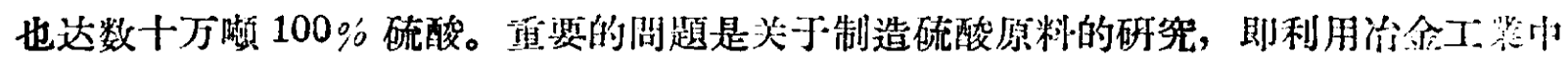

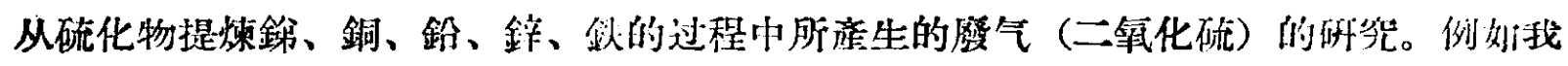

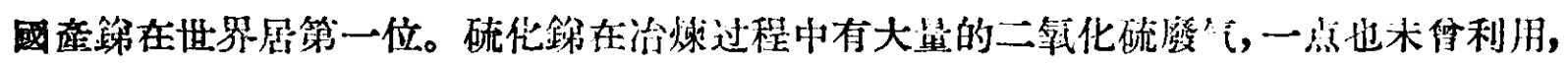

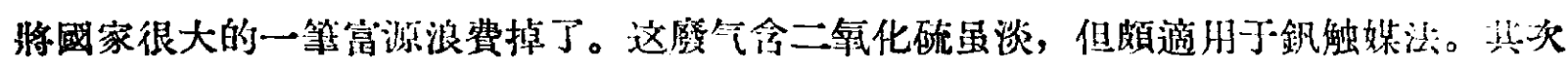
是如何大量利用浮选法所冴下來约硫化尾砂。未解决的間題是在磁硫化狄的尾砂。因其

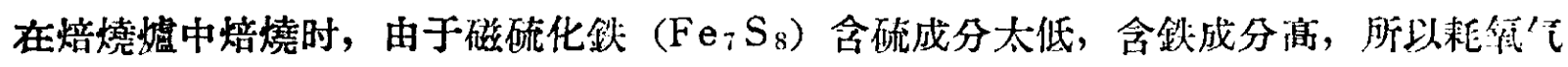

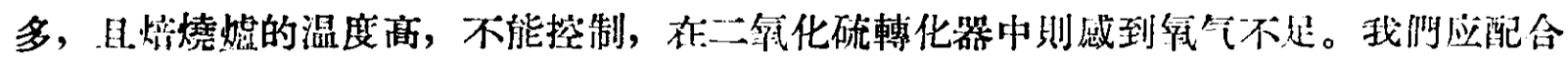

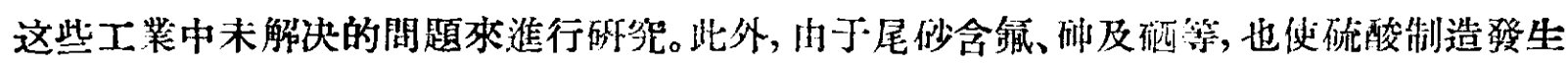

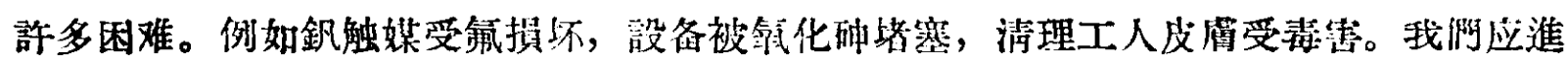

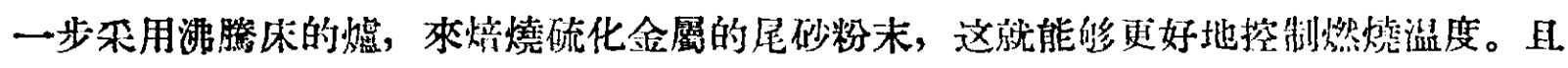

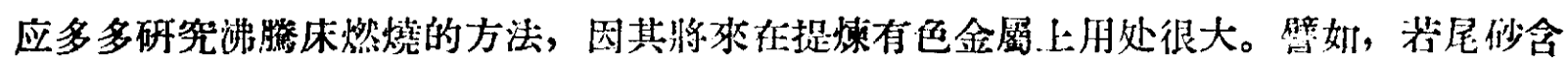

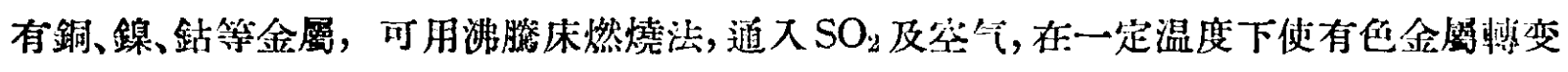

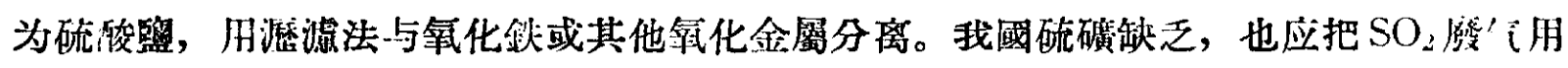

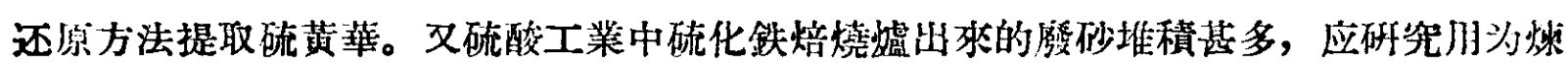
铁原料。

此外，用空气分离器可取得疽集的氧气，它在冾金工業研究中是必要的設备。上迅 


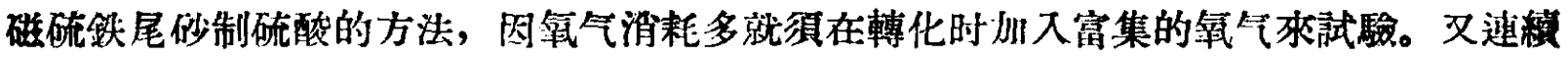
法制造水煤气發生嘘也需要氧气，而煤炭完全气化法更需要氧气。随着國家大規模工業 發展, 氮气的需裂一定激增, 試驗研究産生大量的廉价氧气是迫切需要的。

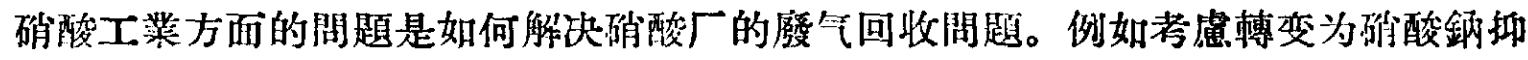

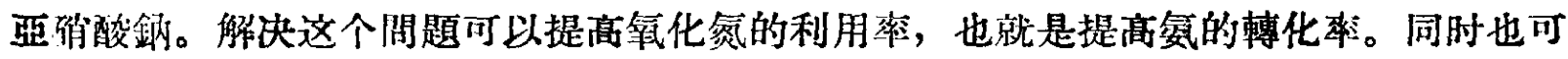
研究利用硙酸厂的庭气, 燃燒去度气中所含的小量氧气与氧化氮, 作为制合成氮的补充 氮气。

留酸应由有机化学工業的氯化水解副產中回收。侧如由苯制造氮化苯, 再經水解轉

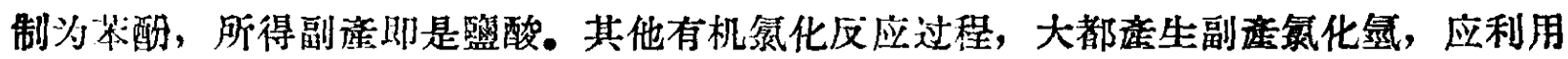
作監酸收回。

磷酸問题在磷肥中討論。

在碱的方而，五年計划規定到 1957 年年產純碱 47.6 万顿，但因國家建設計划提前 完成及加快加多厉, 所需供应更大。我國目前大連、塔活兩厂量到1957年向难㴖足工 業要求, 应以天然碱补充。要積極研究天然碱的加工处理方法, 使質量与化学碱相等, 方能符合工業的要求。天然碱的副品，如芒硝、食監、氮化鉀、硼砂、矹酸、滇、氯

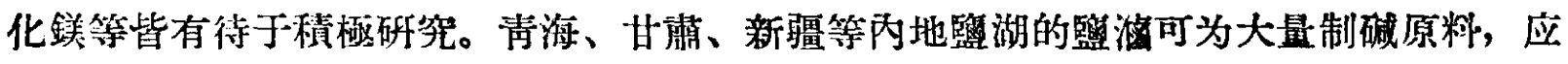
研究朋以制造純碱, 既可利用內地資源, 又符合國防条件。

我國人民現仍用純碱發面，因碱性强而使面包發黃，科有碍健康。因此应制造碳酸

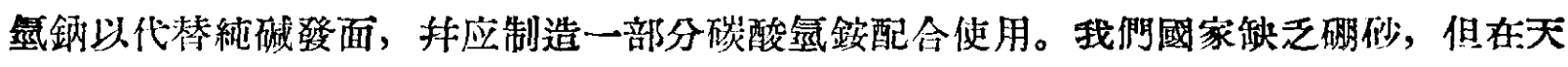

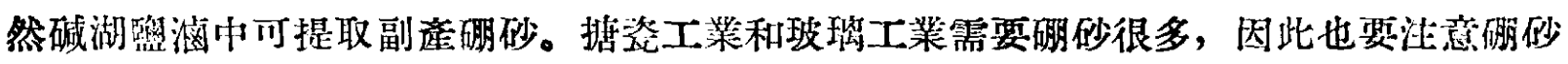

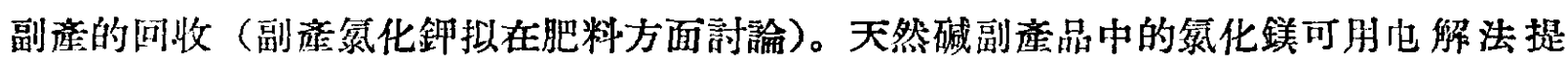
出金屬鉄。也可山海水中提取氮化鉄，然后用电解法提哂金屬鎂。鉡是很重姴的金屬，

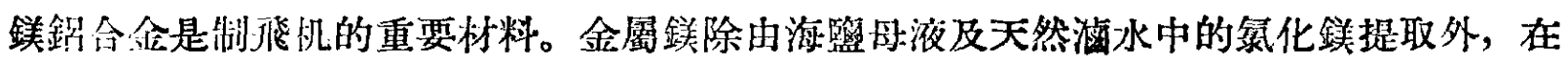

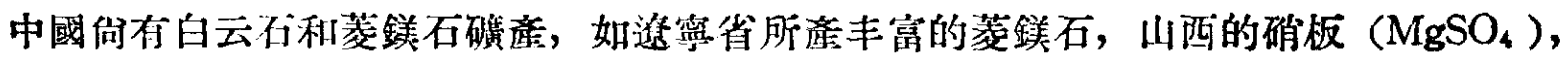
均可作为制全留鎂的原料。

在肥料方面，有氮肥、磷肥、釗肥三种。氮肥我們已有硫酸鉸与确酸銨，技衡頗有

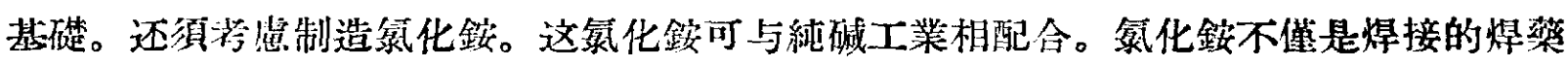
及干池池工業的原料, 也是莀田的良好肥料。“侯氏碱法”即結合氮肥与純碱爽制造。这

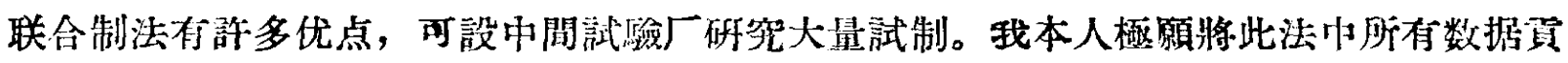
献給占家作为提前完成計划的储礼。

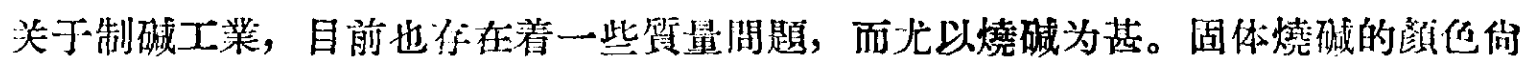

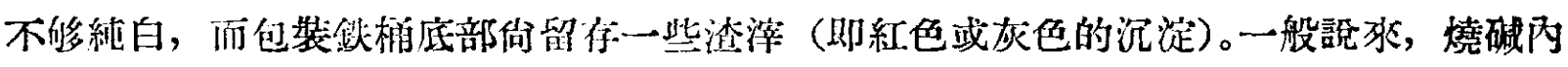

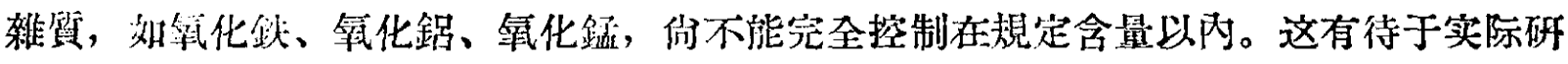

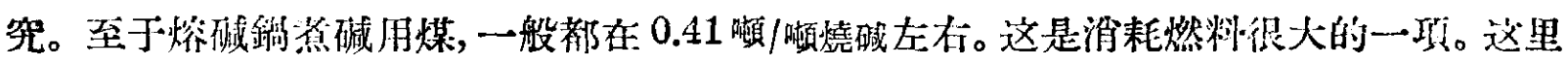

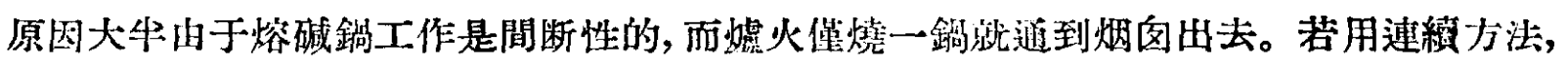
使火烟通过数鎘，就可以大大節省用煤。我國燒碱厂向末有用連縝制造固碱法的。如果 一系列的熔碱錦, 作梯階狀裝置, 碱液可由最高一鋿逐渐流到最低一鍋。煤在最低一鎘

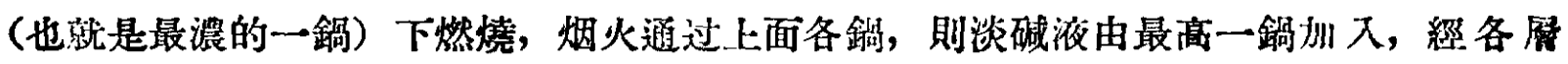




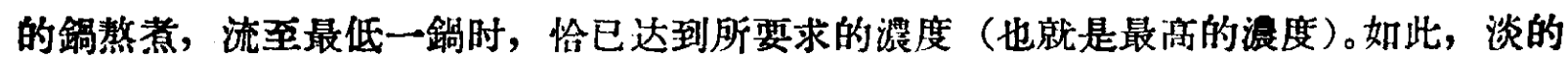

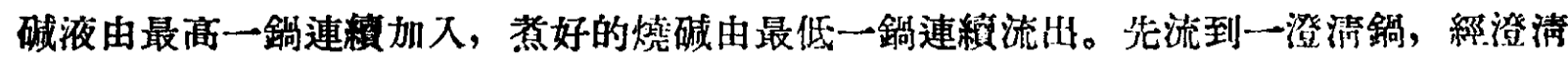

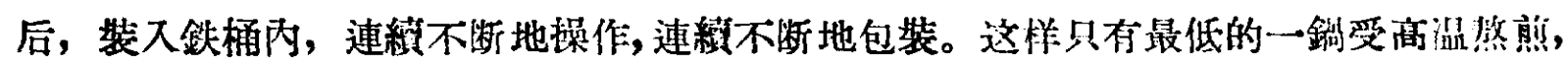

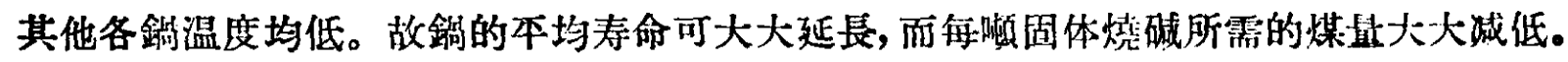
但这方法在中國向末用过，应先経过中間試驗厂研究試制。

氮肥中应研究尿秦肥料，因为尿辨的原料（氮及二氮化碳）在合成氮厂中都有。尿 素肥料含氮高，且不像硝酸銨容易湖湿結地。故可設立中間工厂研究其連維性制造方泣， 不用單程通气，而用循环避气法。

为了節省投省, 直接用空气中的氮气制造硝酸, 可用气体燃燒方法 (不用电力), 經 反复預热达到副温（如在 $2,200^{\circ} \mathrm{C}$ 以上）, 使空气中氮气与氧气化合制造硝酸。这可不需 要先制造合成氨，而㨁接得到硝酸，簡便实多。这法在國外已䋊試驗成功。永利公司从 新也試驗过, 以后因抗战滕利复員, 未繼維谁行.

磷肥方面应發展硝酸磷肥, 以砣酸代替硫酸。另外应做三料磷肥(重过磷把), 則以 磷酸自身代替硫酸。这就必須先制造磷酸。同时磷酸也能用之于工業。磷酸肥料有“安 程粉”（磷酸鉸）及磷鉀混合肥料。这雨种肥料都应研究，磷釷肥料可結合攀石的研究

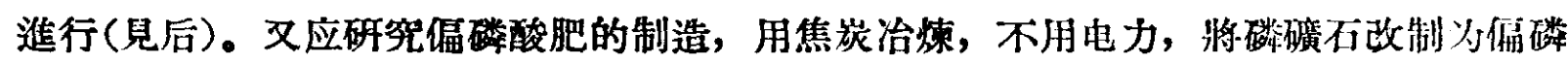

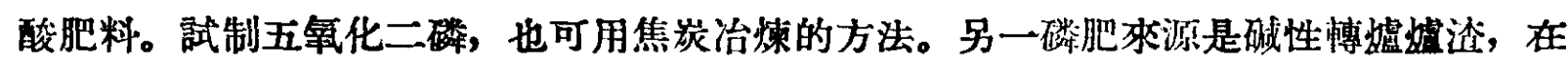

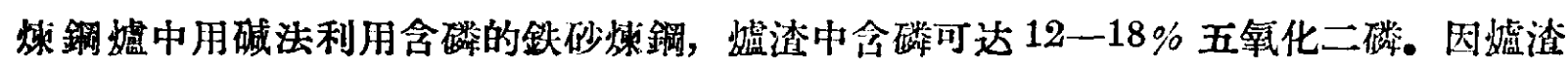
已經过高温层燒, 只須磨碎即可使用, 且易为農倠物吸收。

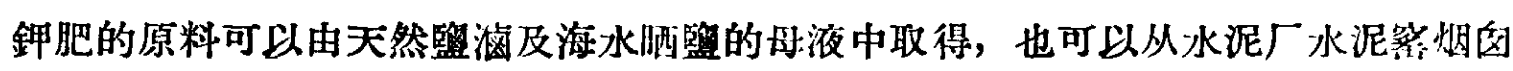
出來的灰磨取得。鉀肥的另一重要來源是礬石，在浙江本陽、安徽盧江、江苏江蜜都有。 这不但可为氧化鋁的原料，也可用以制造硫酸鉀。过去黄海化学工業研究㼛已做过很多 禁不的研究工作。現在可以考慮建設中間試驗厂大規模試制。

我國在释济建設当中，首先注意鋼鉄工業的發展，則煤焦工業亦將会相应地迅速㖟 展。郮以燐焦厂所斑生的为量極大的煤气，应留作合成汽油制造原料，合成訶醇制造原 料，或合成氮制造原料。焦婸煤气应裂化作一氧化碳及氯气來源，不可当作燃料燒去。 为了更合理地运用國家資源，我們应斯研究用部分的氧化法由甲烷等碳氢化物軧化为一

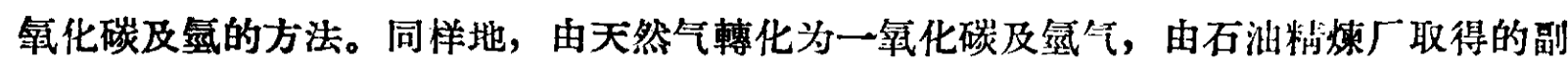

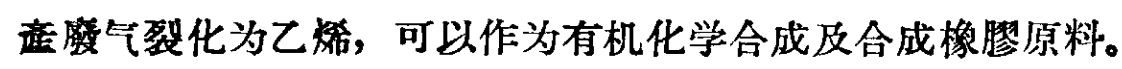

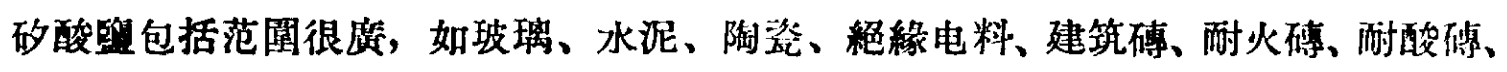
水玻璃等。另有耐滈温的金屬陶瓷及有机矽高分子望料。其中有許多閌題应深入政究。

关于催化剂, 工業上需要的有合成氮工業的氨催化剂, 一氯化碳氧化催化剂, 接触 法硫酸催化剂 (即釩催化剂), 以及一氧化碳加氢的合成汽油的催化剂、不汕致化催化 剂、有机叠合三氮化鋁催化剂等等。这些催化剂都应有系統、有計划地研等自制。号外,

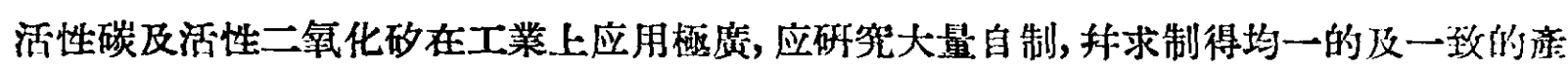
品。合成氮催化剂國內可以自制, 品翼地相当优良。但仍須進一步研究制造能耐中滥的 合成氨催化剂。制接触硫酸的釩催化剂國內也可以自制, 質量拌不遜于航本品。惟釩金 的來源國內向不能供应, 应急研觉, 以便能由國內大量供給钒催化剂的原料。其他催 
化剂（如水煤夻轉化催化剂）都应更進一步研究，提商其買量与性能。

結合有机叠合催化剂的研究，应例究高分子化学塑料制造与其原料的制备。在原料

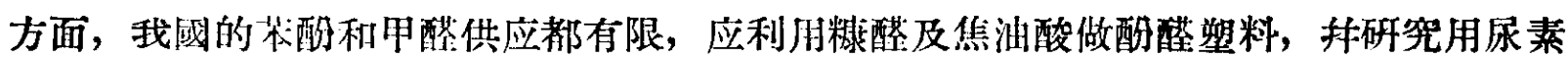

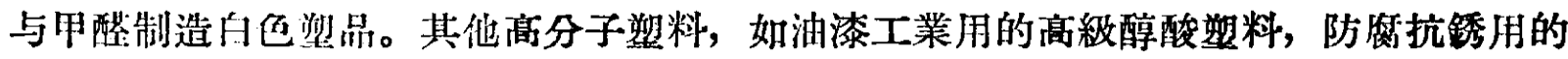
聚氯乙烯, 均有待研下总。

現在焦沁副產品中焦油酸尚未光分利用。随着鋼鉄工業的發展，槵焦工業也迅速發 展，焦油应好好利用。一部分焦油可以用商压加氢的方法制造合成汽油，另一部分可提 取焦油酸朋于有机商分子化学方面，做塑料及染料中間品，抹作为制造藥品及消毒剂的 原料。又目前煤焦副產品中的苯、甲苯等等現在多牛充为內燃机的燃料使用, 这是不合 理的。菜現僅作为家庭防䗆用，应当用來制造苯二甲酸䣶，用于制醇酸樹脂，用到鄚料 及洲漆工業上去。这些原料利用開題都急待研究。

醋酸纖維不但是优良的人造纖維,且是不易着火燃燒的纎維, 是影片工莱主至原料。 应研究大星自制, 以供制造膠片应用。

其他如煤的低温蒸餾，產生牛焦及商热量的煤气，又座生宝貴的低温焦油，可以充 为有机化学合成工栄的制造原料。牛焦的利用与高热量煤气的应用亦应淮行全面的研 究。

在石油工業研究方面，应考虑制造航空潤滑油（低温）及荡温蒸汽(过热)讯和油。 將來柣路机車将改用过热的高温蒸汽, 能耐到 $400^{\circ} \mathrm{C}$ 的高温汽畋油将是迫切需要的。

高分子化学的范国很廣，包括了各种塑料、橡膠及油漆等。如耐高温的有机聚矽塑 料, 在电动机及發电机中已大舅使用，应抓緊研究。人造橡翏是一大工業，我們应多多 研究。其原料用酒精或用乙炔，或用石油提煉厂的廢气（如乙烯等）須要决定。人造橡 膠的主要間題是原料來源問題。应結合我國原料來源，來研究人造橡膠的合成方法。高 分子化学中的有机化学塑料也可应用來做净水的离子交換剂。这是制备銆㠊給水及工業 用水 (如人造絲工業、紙漿工業等) 所必需的。

随着農業合作化的高潮, 農業对工業的要求主要有三項: (一) 化学肥料; (二) 消除 病虫害的䒚剂; (三) 深耕的拖拉机。除了拖拉机屬机械部門外, 其他兩項(肥料与農樂) 須仰給于化学工業。其生產技術有待于化工研究，应能不断提高。晨肥研究已如上迅，

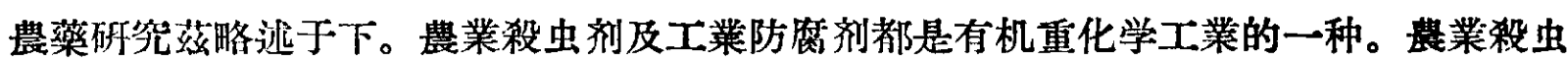
剂应結合电解燒碱工業來考慮。如用氯气制造 DDT、666、氯酸鈵、三氮硝基苯、氯化乙

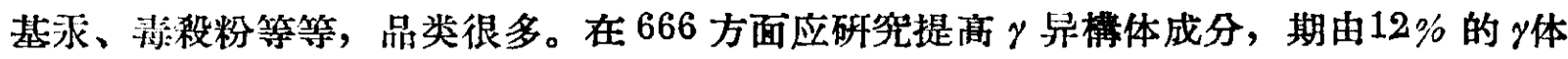
提廊到 $25 \%$ 以上，使得恔濃的殺虫剂。另外如E059、E605、20YT、24DY、氯化苦、砷酸鉊

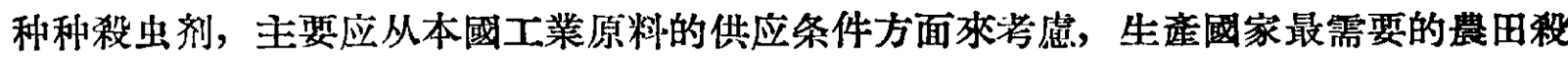
虫剂。在电解工業方面，电解所必需的炭精板目前向不能自制。应即研究制造炭精电極 的技術來供应炭精板 (非圆棒)。防腐剂为工業上保护設备所必需, 油漆固是一种防㻺剂, 但油漆之类大都不能耐酸碱的侵蝕，尤其是对高温及燒碱。目前只有塑料可以抵抗酸碱 (如聚氯乙悕等)。我國有生漆(大渎)，頗能耐酸碱及硫化物的侵蝕。故对生漆性能及其

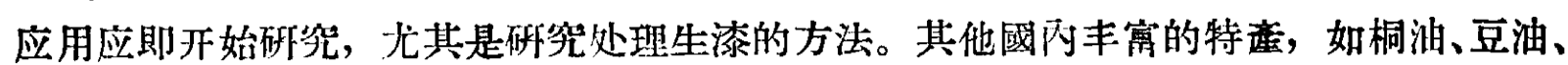

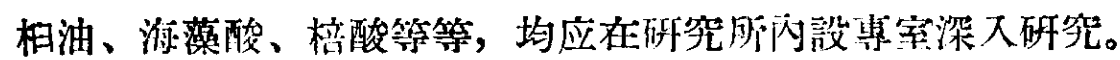


另外应研究桸有金屬, 如釷、铁、钝、鈷、铅、鈤、鈾、鈹等等, 皆工業所迫切需

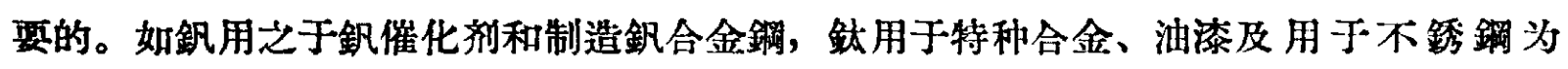

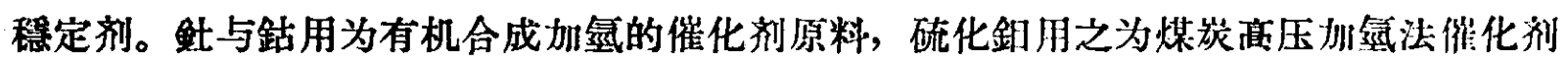
等。中國独居石中可煉釷, 用为原子能的原料。配合原子能的研究, 原子堆的棈造以及 同位素在工業、農業、地算及医藥上的应用, 都急待研究。我國在苏联的帮助下将迅速 地發展原子能和平利用的研究。化学研究方面, 应及早配合原子能研究, 提㶱原子反应

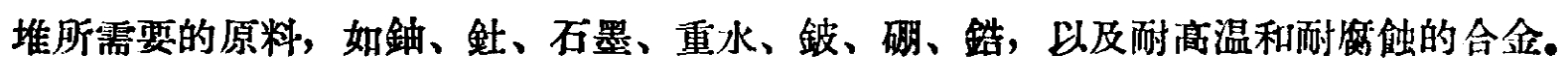
都这有助于我們推度原子能的和平利用。

最后, 化学研究用的無机化学試剂, 質量与数量均不能完全符合需要, 急需研究精 制, 庶能滿足化学試驗工作的要求。

化学研究工作, 应有計划、有組織、有領導地進行。我們科学院技焉科学研究工作, 一方面应与生部門各研究所分工合作, 另一方面应与國內各大学研究室取 得密切联 系, 既免工作重复, 复得彼此配合。化学研究是站在化工建設的最前䋐, 它是为設棓部 阴提供技術設計数据的。

随着社会主义縒济建設的“快、又多、又好、又省”的要求，我侧技術科学研究人 员現在是远远落后于要求的。因为新生力量須从基層幹部敉养提拢, 故对技術科学人真 培养訓練工作实所必需, 且須加速加强。一方面須在國內高等学校对技術科学清年多多

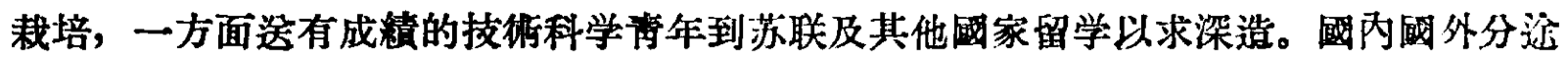
齐淮, 庶能迎头赶上。

应当指出，对國內老的科学人員也須考慮如何發揮其潛在力量。在老的科学家中， 如果有学用不符合或者工作不適管之处, 可予以適当的分配与安排, 使其發找应有的作

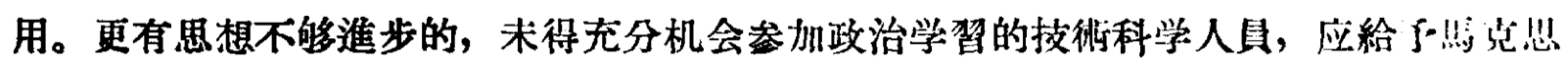

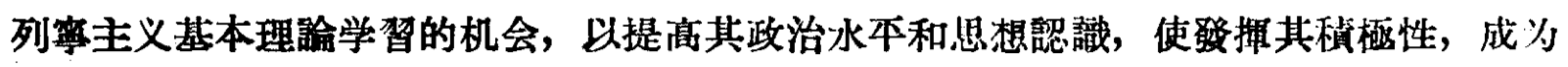
科学研究工作中的積極分子，更好地为社会主义建設服务。

以上是我僻目前化学工業技術中存在的一些研究問題, 也就是第一个五年計划中的 1956 及 1957 这兩年中应当解决的間題。其中有某些部分, 如偏磷酸肥料研究、高級望料 研究等等, 可稍延䜌到第二个五年計划中, 甚至第三个五年計划的初期顺序解决它們。 这就作为远景研究工作一部分來看, 也是可以的。我們有信心、有决心可以及时地完成 这些迫切任务, 滿足國家加速社会主义工業化的要求。我們更要貺硯業業, 勿使認識落 后于实际, 計划落后于要求。只要依靠党和毛主席的正确領導, 就能够勝利地完成或超 額完成这些科学研究工作任务, 讲保証我國的化工科学技術在今后十二年以內达到惐际 水平. 